\title{
Icebreakers for Adults ${ }^{1}$
}

\section{Taylor Nash and Megan Stein²}

\section{Introduction}

Building rapport is key when creating a team culture. As groups change over time, it is imperative to continually reintroduce and reacclimate new team members to long-standing teammates. Leaders of groups that undergo constant change, like those whose jobs involve volunteers, may find it challenging to find innovative ways to bring people together. Icebreakers are quick, low- or no-cost activities that allow individuals to get to know the people around them and serve as a means to build trust and openness in a low-stakes environment. This document outlines strategies to use when building a team culture and gives examples of simple activities to build rapport within teams or groups

\section{Building Team Culture}

Regardless of why groups form, they follow the same process of development. Teams go through five stages in the same cyclical order: forming, when teams are orienting and acclimating; storming, when conflict arises; norming, when teams are becoming cohesive; performing, when teams are at their peak efficiency; and adjourning, when teams complete their task and disassemble (Tuckman \& Jensen, 1977). The forming stage is critical to the development of team culture. Team culture is defined by the set of values that are adopted and shared among team members (Chong et al., 2018). Without the foundation of trust and respect that is created in the forming stage, team culture fails to form (Chong et al., 2018; Tuckman \& Jensen, 1977).

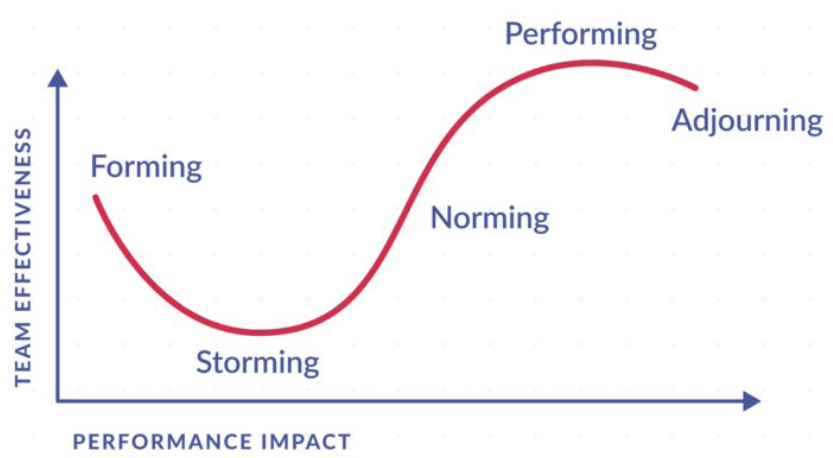

Figure 1. Tuckman's Model of Group Development. Credits: ADCI Solutions

\section{Using Icebreakers}

Icebreakers are a great way for teams to develop trust and begin to identify shared values. Typically, icebreakers are used at the beginning of gatherings, such as meetings or training sessions. They are led by the meeting host or leader of the organization. As the leader, it is imperative to approach these activities in a positive light. All team members should be encouraged to participate to ensure they are active in the group's forming stage. Effective icebreakers have the following qualities: all should have the ability to participate; the activity should teach participants something about those around them; and the activity should be quick. When planning icebreakers for adults, be cognizant of possible mobility concerns or issues.

1. This document is AEC693, one of a series of the Department of Agricultural Education and Communication, UF/IFAS Extension. Original publication date May 2020. Visit the EDIS website at https://edis.ifas.ufl.edu for the currently supported version of this publication.

2. Taylor Nash, graduate assistant, and Megan Stein, lecturer, Department of Agricultural Education and Communication, UF/IFAS Extension, Gainesville, FL 32611.

The Institute of Food and Agricultural Sciences (IFAS) is an Equal Opportunity Institution authorized to provide research, educational information and other services

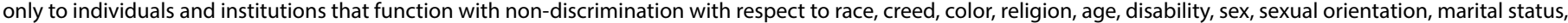

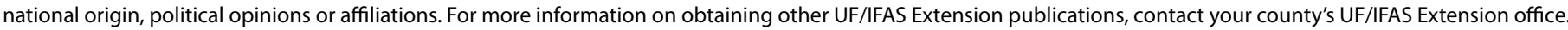
U.S. Department of Agriculture, UF/IFAS Extension Service, University of Florida, IFAS, Florida A \& M University Cooperative Extension Program, and Boards of County Commissioners Cooperating. Nick T. Place, dean for UF/IFAS Extension. 


\section{Icebreaker Examples}

The following activities have been outlined to help meeting hosts or team leaders plan icebreaker activities. Instructions for the activities as well as potential required materials can be found for each experience.

Things in Common-Participants will find commonalities among the group.

\section{No Supplies}

Divide the participants into equal-sized groups. Groups can be of two to ten people, depending on the number of participants. Challenge the group to find five things they have in common beyond the obvious (e.g., they are all human, they are all at this event). Have each group share their five commonalities with the large group. The presenter should focus discussion on the similarities that exist among the group even though they are unfamiliar with each other.

One Chain-Participants find commonalities that connect them all.

\section{No Supplies}

The participants' task is to find things they have in common with others in the group. The goal is to see how long a chain the group can create, linked by commonalities. While participants are walking around introducing themselves to one another, if participants identify a commonality, they will become linked. The ends of the chain will then find something they have in common with different people. With determination, the entire group should be able to get in one line. As a presenter, you will be the final link in the chain that creates a circle. Find something you have in common with the individuals at the ends of the chain. Discuss how the group is one team held together by the similarities we have. Recommended for groups of 15 to 40 individuals.

Your Logo-Participants create logos that represent who they are.

\section{Supplies: paper and writing utensils, 1 per participant}

Have participants write down the three most important things in their life. On the paper, participants will use the items listed to create a personal logo that represents their values (e.g., if a participant has three kids and loves being on a lake, they may draw three waves as their brand). As the presenter, you should share an example about yourself. If the group is fewer than 15, have participants share it for the group. Larger groups can share their logos in small groups.
Partner Stories-Participants introduce each other from prescribed questions.

\section{No Supplies}

Identify three fun-fact questions for your group (e.g., favorite hobby, best vacation, current goal). Participants will get in pairs, introduce themselves, and answer these questions. Listen close. When the group gets back together, participants will introduce their partner based on what they remember. Recommended for 16 people or fewer.

My Motto-Participants create billboards of a motivational quote.

Supplies: paper and markers or colored pencils, 1 per participant

Each participant will receive a piece of paper and something to write with (markers recommended). Challenge participants to think of their favorite quote that keeps them motivated on a tough day. Write the quote on the piece of paper. When doing introductions, participants will share their motivational piece for the group. Hang the quotes on the wall as motivators throughout the event. Groups of fewer than twenty are recommended to share for the whole group. Larger groups are recommended to share in small groups.

Grocery List-Participants shop for similarities in the group.

\section{Supplies: notecard and writing utensils, 1 per participant}

When creating a grocery list, you only write down the things you need, but while in the store, you always pick up more than what's on your list. Have participants write down a list of three to five facts about themselves. When the group is ready, have them go "shopping" for people who share similar facts, checking off their list when they find someone with that item as well. And just as you pick up extra things in the store, if a participant also identifies with someone's fun fact, they can add it to their list and check it off. Recommended for groups of 15 or more.

What's in Your Pocket?-Participants will describe themselves using an object they have with them.

Supplies: random objects

Participants will be challenged to find something they brought that represents who they are. Participants will 
have two minutes to find an object and prepare their introduction. Objects may come from their pocket, wallet, purse, etc. An example introduction could be using a key that represents their home and family or sunglasses because they love the beach and traveling. Groups of fewer than twenty are recommended to share with the whole group. Larger groups are recommended to share in small groups.

Graph Us-Participants text in answers to create graphs that represent the group.

Supplies: all participants must have the ability to text or access to the internet, a source to present the data on (screen, projector, laptop)

Before facilitating this icebreaker, it is important to ensure all participants can send text messages or log on to the internet. Using the website https://www.polleverywhere. com, the facilitator will create a free log-in and, using the instructions on the website, develop questions for the group. Questions should be related to getting to know other group members. In the training, log on to the website and activate the questions. Participants will text in the code provided on the web page to the number identified. After the initial message, participants will text in the answers to the questions you have provided. When a text is sent, the answers will anonymously appear on the screen, including group totals. In this icebreaker, participants will learn what similarities and differences exist within the group.

\section{References}

Chong, M., Shang, Y., Richards, M., \& Zhu, X. (2018). Two sides of the same coin? Leadership and organizational culture. Leadership \& Organization Development Journal 39(8), 975-994. https://doi.org/10.1108/LODJ-05-2017-0122

Tuckman, B. W., \& Jensen, M. A. C. (1977). Stages of small-group development revisited. Group \& Organization Studies 2(4), 419-427. https://doi. org/10.1177/105960117700200404 